\section{External Light Source Visualization in Percutaneous Endoscopic Gastrostomy Tube Placement}

Percutaneous endoscopic gastrostomy (PEG) is the procedure of choice for achieving long-term enternal nutrition in patients with an intact gut and inability to swallow. A low procedure-related mortality and morbidity have been noted previously (1). Using all currently described methods, transillumination of the anterior abdominal wall via the endoscope is recommended (1-4). There is a significant time delay in transillumination, as well as a failure rate related to the inability to adequately transilluminate the anterior abdominal wall (1). We report here on a modification of this proccdure that significantly increases the ease of the PEG insertion and reduces the operating time.

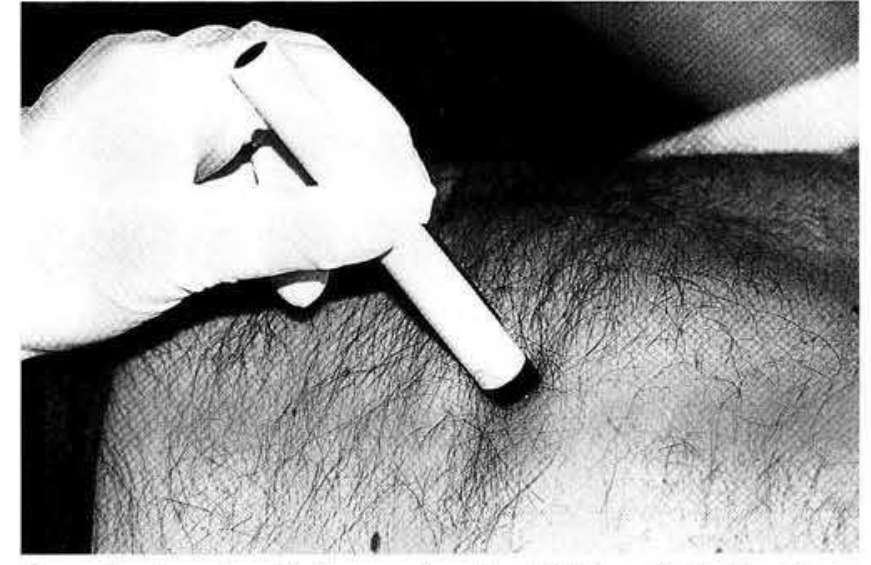

Figure 1: An external light source (pen-torch light) applied to the anterior abdominal wall. 
An external light source (pen torch-light) is applied to the left anterior abdominal wall at the preferred site of PEG insertion (Figure 1). The transilluminated segment of the abdominal and gastric walls is then clearly visualized endoscopically (Figure 2). The optimal site for PEG insertion is achieved by accurate positioning of the external light source, with modification of the pressure applied. Blood vessels can easily be avoided using transillumination.

The benefits of this modification include better positioning, both externally and intraluminally, reduced operating time, and a potential reduction in the complication rate related to bleeding. It is of particular benefit in patients with previous abdominal surgery and obese patients. This technique has been sucessfully used over the last six months at our institution, with acceptance by the endoscopists using the method.

\section{Badov, J. R. Lambert}

Dept. of Gastroenterology, Mornington Peninsula Hospital, Melbourne, Victoria, Australia

\section{References}

1. Larson DE, Burton DD, Schroeder KW, et al. Percutaneous endoscopic gastrostomy: indications, success, complications, and mortality in 314 consecutive patients. Gastroenterology 1987; 93: 48-52.

2. Mellinger JD, Ponsky JL. Percutaneous endoscopic gastrostomy. Endoscopy 1994; 26: 55-9.

3. Gauderer MW, Ponsky JL, Izant RJ. Gastrostomy without laparotomy: a percutaneous endoscopic technique. J Pediatr Surg 1980; 15: 872-5.

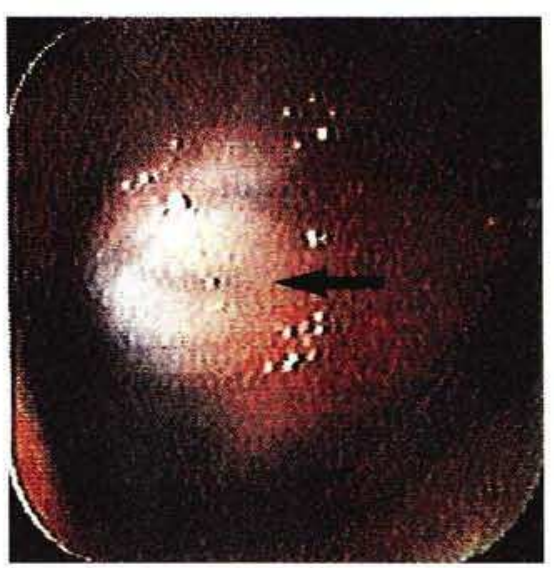

Figure 2: The transilluminated segment of the abdominal and gastric walls visualized endoscopically. The external light source (arrow) and blood vessels are clearly visible.

4. Ponsky JL, Gauderer MW. Percutaneous endoscopic gastrostomy: a nonoperative technique for feeding gastrostomy. Gastrointest Endose 1981; 27: 9-11.

Corresponding Author

D. Badov, M.D., B. S.

Dept. of Gastroenterology

Mornington Peninsula Hospital

Hastings Road, Frankston

Melbourne, Victoria 3199

Australia

Fax: $+61-3-9784-7278$ 